\title{
IDENTIDADES DOCENTES ENTRE MUNDOS \\ DISCURSIVOS EM DISPUTA: FORMAÇÃO DO \\ PROFESSOR, LETRAMENTOS E DESENVOLVIMENTO
}

\section{TEACHER IDENTITIES BETWEEN DISPUTING DISCURSIVE WORLDS: TEACHER CONTINUING EDUCATION, LITERACY AND DEVELOPMENT}

\section{Elvira Lopes Nascimento* Paula Baracat De Grande**}

\section{RESUMO}

O presente artigo busca analisar as identidades docentes construídas, negociadas e disputadas no processo de inserção de uma professora da escola básica em um curso de Mestrado Profissional. Para isso, selecionamos excertos de uma sessão de autoconfrontação realizada após a conclusão do curso de formação. Partimos do arcabouço teórico do Interacionismo Sociodiscursivo e da Engenharia Didática da Escola de Genebra, perspectivas estudadas pela professora participante da pesquisa para a escrita de sua dissertação de mestrado. Para a análise das identidades, mobilizamos a perspectiva sociocultural dos Estudos de Letramento, o conceito de identidade como múltiplo, fluido e construído discursivamente, e o conceito de vozes sociais, para compreender se o processo de construção de identidades em mundos discursivos em disputa - a escola e a universidade - resulta em desenvolvimento profissional da professora. Os resultados salientam a importância de se considerar a formação como um processo identitário, que envolve uma construção do que é ser professor na contemporaneidade.

Palavras-chave: identidade docente; autoconfrontação; desenvolvimento.

\section{ABSTRACT}

This paper aims to analyze the identity construction, negotiation and disputation in the entrance process of a teacher of the basic school in a Professional Master 's course. For this purpose, we selected excerpts from a self-confrontation session held after the completion of the Master course. We start from the theoretical framework of Sociodiscursive Interactionism and Didactic Engineering of the School of Geneva, perspectives studied by the teacher participating in the research for the writing of her master's dissertation. For the identities analysis, we mobilize the sociocultural perspective of Literacy Studies, the concept of identity as multiple, fluid and constructed discursively, and the concept of social voices, to understand if the process of constructing identities in disputed discursive

\footnotetext{
* Universidade Estadual de Londrina, Londrina (PR).Brasil.elopes@sercomtel.com.br

** Universidade Estadual do Paraná, Apucarana (PR). Brasil. pauladegrande@gmail.com
} 
worlds - the school and university - result in the teacher's professional development. The results highlight the importance of considering teacher continuing education as an identity process, which involves a construction of what it is to be a teacher in the contemporary world.

Keywords: teacher identity; self-confrontation; development.

Resultados alcançados pela educação básica na escola pública brasileira têm suscitado calorosas reflexões de ordem política, social e cultural sobre o pensar e o agir relacionados à educação. Entretanto, o que dizem os professores? Como realizam seu trabalho em situações concretas do exercício da função? Que elementos o constituem? Que implicação a relação entre esses elementos gera nas identidades docentes em mundos discursivos em disputa?

Esses questionamentos impulsionam as reflexões sobre a problemática da formação continuada de professores da educação básica e tornam relevante a nossa participação no debate que envolve múltiplos aspectos em função das diversas realidades sociais que vivenciam os professores em seu efetivo fazer profissional.

Com o objetivo de discutir as identidades docentes construídas, negociadas e disputadas no processo de inserção de professores em curso de formação continuada e a relação com seu agir na educação básica, investigamos o trabalho de uma professora de língua portuguesa nas atividades desenvolvidas durante uma sequência de formação (SF) ${ }^{1}$, em sua participação no ProfLetras na Universidade Estadual de Londrina. Por aglutinar diferentes etapas da formação, entendemos que essa professora passa a participar, de maneira periférica ou centralmente, de mundo sociais e discursivos distintos (HOLLAND ET. AL, 2003), em que identidades contrastantes são negociadas nos diferentes espaços sociais relacionados à sua inserção no curso de pós-graduação: a escola básica em uma pequena cidade e a universidade de prestígio, constituindo dois contextos de participação em que se entrecruzam: as vozes sociais que clamam pela inovação das práticas educacionais; a realidade do coletivo de trabalho na escola de origem e os saberes dos experts, necessários à formação. Na totalidade complexa constituída nesse processo, confrontam-se identidades em conflito pelo entrelaçamento de múltiplos mundos discursivos.

Em um contexto em que o professor é frequentemente responsabilizado pelos problemas da educação brasileira e sempre convocado a "se reciclar" ou "se capacitar" em cursos de formação continuada, não se pode negligenciar a problemática sobre como o professor lida com a circulação por esses diferentes

1. A SF compreendeu atividades teóricas e práticas da disciplina Gêneros discursivos/textuais e práticas sociais, na Area de Concentração Linguagens e Letramentos, no Profletras - UEL, 2015. 
espaços sociais e pelos discursos neles disponíveis, mobilizados pelos sujeitos com os quais interage, e sobre como constrói identidades mais ou menos fortalecidas nesse processo. Tal reflexão é crucial para que as universidades e outras instâncias que oferecem formação docente repensem seu próprio fazer e os currículos oferecidos para esse fim, uma vez que compreendemos que o processo de formação do professor e seu letramento são identitários (KLEIMAN, 2009, 2013).

$\mathrm{O}$ agir representado por professores, durante e após a formação, apontam indícios da tensão vivenciada por eles ao se deparar com perspectivas de trabalho propostas no curso em contraste com os saberes profissionais internalizados em anos de experiência profissional e a expectativa de retorno à escola de origem com um certificado do mestrado obtido no Profletras, diante da "obrigatoriedade de introdução de práticas inovadoras". Por essas razões, propomos uma reflexão sobre os dados gerados em textos de entrevistas de autoconfrontação ao trabalho de sala de aula que mostram o processo de construção de identidades profissionais vivenciado por uma professora nesse percurso de formação.

Para isso, este texto, primeiramente, discute questões relacionadas aos fundamentos teóricos e metodológicos pressupostos na ementa de uma disciplina do referido curso de formação, ministrada pela então orientadora da professora participante, que se baseia no Interacionismo Sociodiscursivo e na Engenharia Didática proposta pelo Grupo de Genebra. Em seguida, abordamos as relações estabelecidas entre a professora Mirna, seus saberes profissionais e as teorias acadêmicas estudadas no curso, como também as questões que emergem desse encontro tanto para a professora quanto para a formadora acadêmica. Na terceira parte de nosso estudo, discorremos sobre a construção de identidades profissionais de Mirna entre diferentes mundos discursivos - da escola e da universidade com base na análise de excertos de autoconfrontação. Por fim, apresentaremos as considerações finais de nossa proposta de discussão.

\section{A FORMAÇÃO CONTÍNUA E A BUSCA POR NOVOS LETRAMENTOS: CONFRONTOS E CONTRASTES}

No dispositivo didático sequência de formação (DOLZ, 2016), a nossa reflexão parte da proposta teórica e metodológica prefixada pela Ementa da disciplina Gêneros discursivos/textuais e práticas sociais que, no conjunto de disciplinas constitutivas do curso ProfLetras, se enquadra na Área de Concentração Linguagens e Letramentos. A partir dos pressupostos da ementa e dos conteúdos programáticos organizados pela docente que ministrou a disciplina, os saberes docentes, o planejamento, a elaboração e 
implementação em sala de aula de materiais didáticos são os instrumentos para práticas formativas cujo objetivo central é oportunizar a apropriação do conceito de gêneros textuais e seus impactos na pedagogização das práticas de linguagem.

A abordagem dessa disciplina consiste em refletir e problematizar a prescrição oficial que está na origem do trabalho com o ensino-aprendizagem de LP no estado do Paraná e na consolidação de um dispositivo didático multiabrangente pelo qual se possa articular os gêneros textuais como conceito integrador das práticas didáticas com a oralidade, a leitura, a escrita e a análise linguística². Com base nos aportes do Interacionismo Sociodiscursivo (ISD) (BRONCKART, 1999) e da Engenharia Didática proposta pelo Grupo de Genebra (SCHNEUWLY; DOLZ, 2004; 2009), o foco recai sobre o ensino de línguas com base em gêneros textuais, nas ferramentas de ensino (tais como os modelos didáticos de gênero e sequências didáticas), no desenvolvimento das capacidades de linguagem e no agir docente nas suas relações entre linguagem e trabalho.

Além disso, a Área de Concentração Linguagens e Letramentos deixa o pressuposto de que a(s) disciplina(s) nela incluídas vão abordar a leitura e a escrita de gêneros textuais multissemióticos. Em outras palavras: os multiletramentos requeridos pelas práticas letradas em que os professores em formação e os seus alunos estão inseridos. Como resultado, nessa Área o rol de disciplinas do curso pressupõe que a metodologia de ensino-aprendizagem deve ir além das práticas letradas escolares fundadas na cultura escrita e impressa, adentrando assim nos multiletramentos (ROJO, 2012; 2013; 2017).

Essa realidade faz da disciplina Gêneros discursivos/textuais e práticas sociais o lugar social para discutir as relações entre as práticas docentes e os multiletramentos na escola. Os participantes discutem textos da bibliografia, apresentam exposições orais, realizam atividades analíticas e implementam situações de microensino (HILA, 2009) que devem funcionar como uma oportunidade para que a turma discuta aspectos que demonstram a dimensão 'conflituosa' do agir educacional relacionada à seleção do objeto de ensino e à elaboração de instrumentos técnicos e simbólicos acionados para a mediação do processo.

2. A disciplina consta no quadro geral do curso como Optativa e, sendo assim, é ministrada no final do curso, quando a maioria dos alunos já elaboraram (e até "qualificaram") seus projetos de pesquisa. Isso não deixa de provocar estranhamentos relacionados ao fato de que nas prescrições oficiais o ensino de leitura e produção de textos deve tomar os gêneros textuais como unidades de ensino, estabelecendo assim a relação entre o ensino de gêneros e o desenvolvimento das capacidades de linguagem dos alunos e o desenvolvimento do próprio professor que adota o trabalho com gêneros em seu contexto de ensino. 
Entretanto, o contexto de trabalho dos professores em formação é o da escola pública. A maioria dos professores-alunos vem de pequenos municípios, de escolas onde a relação ensino, currículo e tecnologias ainda não se encontra a serviço das práticas sociais escolares. O livro didático, a lousa, o giz (e muito raramente o notebook do professor conectado ao datashow e projetado na tela) ainda são os recursos didáticos disponíveis ao professor, relacionados a uma mentalidade e a uma concepção de ensino em que se daria a transmissão de conteúdos controlados pelo professor a alunos passivos. Além disso, o próprio espaço físico das salas não favorece uma interação que promova o trabalho colaborativo e o protagonismo do aluno, ou seja, que permita a integração do currículo prescrito e estabelecido com o aprendizado com base nas experiências e experimentações dos alunos (DCEs-PR).

Nesses contextos escolares, o que se ensina e se aprende é decidido, estabelecido e planejado no cronograma inserido no paradigma da aprendizagem curricular (LEMKE, 2010), ao contrário do paradigma da aprendizagem interativa que, segundo o autor, produz uma mudança radical na relação entre alunos, objeto de aprendizagem e o professor no papel de mediador. Neste paradigma, a pedagogia dos multiletramentos (ROJO, 2012) traz impactos profundos ao currículo tradicional e à lista de conteúdos estabelecidos previamente para serem ensinados, constituindo projetos pedagógicos que implicam o uso das tecnologias digitais, produção colaborativa, produções individuais significativas (e não reprodutivas) e socialização dos resultados.

\section{TENSÃO EMERGENTE: ENTRE OS APELOS À INOVAÇÃO E OS SABERES PROFISSIONAIS DA PROFA. MIRNA}

Ao enveredar pelo planejamento e elaboração de materiais didáticos como parte constitutiva da referida disciplina no curso de formação, os professores-alunos são submetidos aos desafios de elaborar uma sequência didática (SCHNEUWLY; DOLZ, 2004) para a aprendizagem com a preocupação de mobilizar o que internalizaram sobre o ensino de gêneros aliado, o mais possível, às possibilidades abertas pelo paradigma da aprendizagem interativa discutido por Lemke (2010) e Rojo (2017; 2013; 2012).

A profa. Mirna, cujo trabalho de conclusão esteve sob orientação da docente que ministra a disciplina descrita, nos diálogos com a formadora, se refere aos desafios que essa "mudança forçada" de abordagem representa para ela. Ela demonstra ter consciência da distância que separa o contexto do trabalho real (MACHADO, 2007) na escola em que atua e o contexto do planejamento de 
uma sequência didática no curso de formação na universidade. Desafio, porque ela sente (e pressente) que tudo aquilo que ela planeja e gostaria de executar vai se acumular em um emaranhado de "coisas para pesquisar, fazer, planejar, levar à sala de aula e propor aos alunos". Ou seja, são "coisas" que vão se acumular como energia que não tem vazão (CLOT, 2010). Ela antecipa o desgaste e a sobrecarga das tarefas organizadas sistematicamente para as atividades escolares de seus alunos.

A profa Mirna está vivenciando um conflito: de um lado, no curso de formação, o desgaste físico e psicológico provocado pelas reflexões e discussões em que reina soberana a expressão "inovação das práticas". Por outro lado, a mesmice dos gestos tradicionais que ela tem repetido ano após ano. Por um lado, ela se depara com uma infinidade de conceitos novos: gêneros textuais, modelos didáticos, sequências didáticas, paradigma da aprendizagem interativa, objetos de aprendizagem digitais (OADs), trabalho colaborativo, protagonismo, etc. Em outro, ela se vê com o livro didático ${ }^{3}$ como única ferramenta para mediar o trabalho com a modalidade escrita dos textos impressos. Na escola em que atua, sempre instaurou em suas aulas formas de trabalho social em que a interação se dá de um para muitos, ou seja, pela exposição frontal dos conteúdos.

A tensão da prof ${ }^{a}$ Mirna é crescente: Onde encontrar OADs? ${ }^{4}$ Como pensar em sequências formativas com OADs? Como elaborar sequências didáticas com gêneros, mobilizando práticas sociais que se encontram no mundo digital? Como conciliar o apelo das prescrições oficiais e da academia e as suas práticas claramente inseridas no paradigma de aprendizagem curricular? Como conciliar as propostas da engenharia didática com o paradigma de aprendizagem interativa? Como atravessar a ponte da abordagem dos textos na forma tradicional? Como romper com saberes e práticas internalizados há longo tempo? São muitas as questões que emergem no processo de formação continuada de Mirna, relacionadas à identidade profissional, ou seja, ao que é ser professor na contemporaneidade.

3. Os livros didáticos atualmente contam com recursos digitais a eles associados, além de serem constituídos cada vez mais por textos multimodais, com propostas que exploram outras linguagens, e não apenas a verbal-escrita. Damos destaque aqui aos usos do LD relatados por Mirna.

4. Durante as aulas na disciplina, buscam-se possíveis OADs no repositório do Portal Dia a Dia da Educação, que apresenta informações a respeito do site de Língua Portuguesa e sobre a Tv Multimídia (Tv Pendrive). Disponível em: http://www.portugues.seed.pr.gov.br . Os OADs disponíveis são: animações, áudios, fotos, filmes, infográficos, jogos on line, selecionados para a disciplina, livros didáticos para download, fábulas, canções e contos dramatizados, livros de domínio acesso a trechos de filmes etc. 


\subsection{0 encontro da profa. Mirna com as propostas da Engenharia Didática da Escola de Genebra}

A disciplina inserida no currículo dessa formação (e ministrada por uma das autoras deste texto) busca, para o ensino de LP, os fundamentos da engenharia didática proposta pelo Grupo de Genebra (BRONCKART, SCHNEUWLY e DOLZ) que tem como focos a transposição didática e as ferramentas de ensino (tais como os modelos didáticos e sequências de atividades didáticas); o desenvolvimento das capacidades de linguagem dos alunos e o agir docente nas suas relações entre linguagem e trabalho.

Assim fundamentados, os conteúdos abordados naquela disciplina tratam de recursos e estratégias apontados pela Engenharia Didática para promover o foco do trabalho a partir do texto, na sua multiplicidade de gêneros orais e escritos em diferentes suportes e usos. Assim, postula-se que se tome o ensino de gêneros por meio das Sequências Didáticas, em consonância com as concepções interacionistas da linguagem que, segundo Dolz (2016, p. 78),

assumem a responsabilidade de conceber projetos escolares, elaborar dispositivos e materiais escolares para ajudar o professor a planificar as formas sociais de trabalho escolar dos alunos, assim como a criar ferramentas para facilitar as aprendizagens, orientar as intervenÇões e os gestos profissionais do professor.

Para o autor, em uma sequência formativa, assume grande importância o estudo e a pesquisa sobre o gênero que será alvo da construção do Modelo Didático do Gênero, que possa indicar ao professor aquilo que seja adequado ensinar aos seus alunos. Isso significa que o modelo didático precisa se sustentar a partir do tripé: desconstrução, descrição e indicação das dimensões ensináveis do gênero (DOLZ, GAGNON, 2015). Na abordagem da engenharia didática, ao estudar um determinado gênero, esse material se torna um instrumento didático a serviço do professor, pois serve para explicitar os conteúdos ensináveis e, ao mesmo tempo, configura-se como mediador do gesto profissional de elementarização/delimitação da transposição didática (NASCIMENTO, 2014), apontando os "objetos potenciais para o ensino" (DOLZ, 2016).

$\mathrm{Na}$ tensão emergente entre a formação que lhe é ministrada e o planejamento do instrumento pelo qual deverá mediar a intervenção junto aos alunos de sua escola, a profa. Mirna "sabe que tem de apresentar" indícios da sua compreensão acerca dos fundamentos teóricos e metodológicos tanto dos textos prescritivos oficiais para a disciplina de Língua Portuguesa, como também dos textos teóricos que fundamentam os saberes específicos do trabalho no que diz respeito ao foco 
nos gêneros textuais e nas propostas da engenharia didática. Ela se vê compelida a agir com base nos aportes teóricos proporcionados pelo curso de formação, conciliando-os com os saberes experienciais adquiridos em quase duas décadas de atividades na escola pública, na disciplina de LP para o Fundamental II. A etapa final da disciplina está condicionada ao trabalho de conclusão do curso que, no caso da prof Mirna, se concretizou no regresso à escola de origem, onde se dá um dos momentos mais importantes dessa formação: a implementação da sequência didática elaborada durante a disciplina e a gravação em vídeo de algumas cenas das aulas.

Em seguida e a sós com a professora Mirna, a formadora recorre a um dispositivo de análise das práticas proposta pelo ISD que, com base no instrumental da Clínica da Atividade (CLOT, 2006; 2010), atualmente tem sido amplamente usado nas instituições de formação dos adultos, e, principalmente, na formação de professores. Trata-se de um método de verbalização da ação fundado na abordagem piagetiana da tomada de consciência sobre uma ação passada, efetivamente realizada, que deve ser compreendida pelo ângulo de seu andamento e da forma como ela foi sentida e vivenciada pelo sujeito.

A autoconforntação consiste em filmar as sequências da atividade de trabalho e em seguida apresentar essas sequências ao trabalhador envolvido, momento em que se dá um debate reflexivo com o formador/pesquisador. A autoconfrontação às cenas videogravadas provoca um debate e, ao fazer emergir controvérsias sobre as condições de realização do trabalho, surge uma nova experiência sobre a atividade.

Assim, e a partir dessa abordagem, a professora Mirna centrou-se sobre a tarefa representada na videogravação, refletiu sobre ela, explicou, justificou e tomou consciência das diversas possibilidades de realização daquelas tarefas, confrontando competências que ela havia desenvolvido em anos de exercício profissional, atribuindo novas significações ao seu trabalho e a suas capacidades.

Sucederam-se vários encontros com a formadora e os textos orais foram gravados e transcritos. Os textos das entrevistas de autoconfrontação foram submetidos ao procedimento de análise propostos pelo ISD (BULEA, 2017) que implica três operações metodológicas: a primeira, que busca identificar os modos de articulação dos segmentos de orientação temática e os segmentos de tratamento temático; a segunda operação, que consiste em identificar os temas tratados ao longo da entrevista e propor uma organização lógica; a terceira, que consiste na análise das propriedades linguísticas dos segmentos de tratamento temático que abordam a tarefa ou o trabalho em foco na entrevista. Essas análises são inspiradas no modelo da arquitetura textual adotada pelo grupo LAF (BRONCKART, 2008): 
a identificação dos tipos de discurso Narrar (implicado ou autônomo) e Expor (implicado ou autônomo). Os "tipos de discurso" apresentam marcas linguísticodiscursivas que os identificam ${ }^{5}$.

Nos textos das entrevistas da autoconfrontação, o tipo de discurso "narração" é quase sempre ausente, entretanto identificam-se ocorrências de "relato interativo" e do "discurso teórico", sendo o mais frequente o discurso interativo, em que aparecem as frases não declarativas (interrogativas, exclamativas, imperativas), as unidades dêiticas referentes a objetos acessíveis aos interactantes ou ao espaçotempo da interação. Observa-se também forte presença de pronomes e adjetivos na primeira e segunda pessoa do singular e do plural e a presença do auxiliar de modo poder, bem como de outros auxiliares de valor pragmático, do tipo querer, dever, precisar, etc.

Nessa perspectiva metodológica, a análise dos modos de expressão da agentividade procura identificar os modos de expressão das pessoas implicadas na atividade de trabalho em foco, dando uma importância ao desdobramento dessa atividade. Essa expressão de agentividade se torna evidente quando a professora Mirna - trabalhador envolvido no agir - se designa por uma das formas pronominais (eu, você, a gente, nós), ou por um nome genérico da sua atividade profissional (os professores). A proposta de análise da arquitetura textual do ISD perpassa também a análise das relações predicativas diretas e indiretas entre o sujeito e o verbo das frases com a finalidade de estabelecer os valores de modalização, os valores aspectuais e os valores de operação psicológica.

Os textos orais gravados nas entrevistas de autoconforntação de Mirna deixam entrever unidades semióticas em ação que demonstram um estado psicológico de tensão e conflito provocado, antes de tudo, pela preocupação em demonstrar que conseguiu atender aos apelos por inovação conforme ela internalizara na disciplina, ao mesmo tempo pela sua busca de justificativas ao agir na sala de aula que, segundo ela própria, "estavam distantes do trabalho planejado".

Ela se refere ao fato de que "antes da entrada no curso de formação, seu material didático de apoio era o livro didático". Ela se refere ao agir no tempo "anterior ao curso" como assentado na posição subalterna à instituição e às diretrizes "impostas aos professores". Em certos momentos, nos diálogos com a formadora, enquanto assiste às cenas gravadas, a professora se refere à "falta de relação entre teoria e prática como fonte de confusões e equívocos durante as aulas". Nas situações de autoconfrontação às cenas de sala de aula, ela se esforça para explicar

5. Para o aprofundamento da proposta de análise no modelo da arquitetura textual adotada pelo grupo LAF (BRONCKART, 2008) remetemos o leitor às obras de Bronckart $(2003 ; 2006 ; 2008)$. 
procedimentos marcados pela sua vontade de transformar gestos didáticos que ela caracteriza como de um "antes" e um "depois" do curso.

As questões que emergem para nós, pesquisadores, giram em torno de: A tensão proveniente do encontro com novas possibilidades e diferentes modos para o seu agir profissional favoreceram um processo de desenvolvimento profissional? Quais os reflexos na professora Mirna da mudança de paradigma que lhe foi proposta? Que identidades profissionais são construídas e negociadas no processo de embate entre esses mundos? As questões relacionadas ao processo identitário da professora Mirna materializado no texto oral da entrevista de autoconfrontação às cenas videogravadas passam a ser o nosso foco de atenção.

\section{AS REPRESENTAÇÕES DO AGIR NA ENTREVISTA DE AUTOCONFRONTAÇÃO}

Concordamos com Kleiman (1998a), quando afirma que a Linguística Aplicada atual está dando uma resposta clara contra a tradicional divisão do trabalho entre teoria e prática, em seus objetos de análise. Antes, o foco da LA era o estudo do aluno e como a sua aprendizagem se processava; atualmente, o professor também passa a ser observado, analisado, justamente pelo fato de haver uma necessidade em se compreender quais capacidades, competências e conhecimentos possui e quais são necessários desenvolver, tendo em vista promover um ensino eficiente e de qualidade e, o mais importante, contribuir para a aprendizagem e para o desenvolvimento dos profissionais da educação e dos aprendizes desses profissionais (BRONCKART, 2008) e, por que não, dos próprios professoresformadores de professores.

Nessa perspectiva, neste tópico debruçamo-nos sobre o agir docente, objetivando identificar as representações/configurações da profa. Mirna sobre as suas ações visualizadas nas cenas videofilmadas. Por representação, no âmbito do ISD, consideramos o conhecimento construído nas negociações ocorridas em interações verbais (BRONCKART, 2009).

Assim, relacionamos as representações a identidades profissionais em construção e em negociação, entre o mundo discursivo da escola e o mundo discursivo da universidade. Para isso, diferentes dados poderiam ser selecionados, desde transcrições das aulas do curso frequentado, a SD elaborada pela professora, sua dissertação de mestrado, as aulas videogravadas dadas após a disciplina em questão. Optamos por enfocar, dentro dos limites impostos neste artigo e com base no escopo da discussão, as sessões de autoconfrontação gravadas, realizadas entre 
a orientadora e a professora em formação continuada, selecionando excertos das transcrições em que o processo de construção identitária está em jogo.

A professora Mirna internalizou a ideia de que é conclamada a assumir um padrão de comportamento que possa ser considerado inovador no sentido de se adequar aos pressupostos do paradigma de aprendizagem interativa, discutido nas aulas da referida disciplina. No momento em que ela se depara com as cenas videogravadas, apresenta indícios de insegurança pela quebra de suportes tradicionais para o trabalho que nos leva a questionar: Qual a implicação desses sentimentos para o desenvolvimento das suas funções psíquicas, relacionadas ao seu desempenho profissional? Até que ponto ela se sente perturbada pela tensão emergente entre os apelos à inovação propostos pelo curso de formação e os saberes há longo tempo testados e postos em prática? Essa tensão pode ser enquadrada como um conflito identitário entre o que era, o que está sendo e o que "tem" de vir a ser? Esse conflito identitário funciona como um "motor" que a impulsiona a continuar, a insistir na assunção da nova identidade em relação à sua profissão? $\mathrm{O}$ seu poder de agir se encontra em choque entre o abandono e silenciamento dos saberes que ela já havia internalizado em anos de atividade profissional e os apelos ao agir "diferente e inovador"?

$\mathrm{Na}$ visão vigotskiana (BRONCKART, 2008), as rupturas resultantes da interação conflitual entre os recursos psicológicos de um indivíduo e os recursos novos que lhe são propostos pelo meio cultural propiciam desenvolvimento. No cerne desse desenvolvimento está a contradição ou o conflito com os "velhos" conceitos. Essa contradição conflituosa constitui a zona de tensão, denominada Zona de Desenvolvimento Proximal (VYGOTSKY [1934]1997, p. 352). Enfatiza Bronckart $(2012$, p.85) que cabe ao indivíduo concretizar esse desenvolvimento a partir da "ruptura que esses conflitos causam ou então permanecer sem alterações na sua evolução desenvolvimental". Nessa perspectiva, segundo Bronckart (2008, p. 122), o desenvolvimento das pessoas tem uma base de coerência global que leva em conta dimensões afetivas, cognitivas e sociolinguageiras e as tomadas de consciência possibilitam uma reestruturação de operações psíquicas nas representações sobre o mundo (físico, social e subjetivo). Portanto, para o autor, a tomada de consciência é parte do processo e é um meio que permite o desenvolvimento do indivíduo "desde que gere uma reestruturação psíquica positiva" (2013, p. 122). Nessa perspectiva, entendemos que "o desenvolvimento humano nada mais é, de fato, que o movimento permanente de atribuição de significações a nosso agir e a nossa vida" (BRONCKART, 2008, p. 183). Então, podemos compreender que a atribuição de 
significações ao agir docente pressupõe uma identidade profissional, ou identidades profissionais que são construídas nesse processo de elaboração de sentidos.

Nas análises a seguir, relacionamos os processos de construção identitária, as oposições entre um eu passado e um eu presente da professora, na relação com os mundos discursivos em disputa dos quais participa, com o desenvolvimento profissional.

\subsection{Identidades em construção e em disputa}

O ingresso na pós-graduação representou uma transformação na vida profissional de Mirna, com consequências não só para sua formação e atuação docentes, como também para sua construção identitária como professora. Mirna passa a circular por mundos sociodiscursivos diversos, em que constrói e negocia identidades algumas vezes conflitantes. As práticas de letramento relacionadas à formação do professor em exercício profissional constituem (ou devem constituir) lugares de negociação e transformação de saberes, identidades e práticas profissionais (KLEIMAN; VIANNA; DE GRANDE, 2013).

Entendemos identidade como relacional, ou seja, como algo que sempre pressupõe a alteridade, sempre pressupõe o que não é (WOODWARD, 2000) pelo discurso. As identidades são construídas pela participação em práticas que são situadas e por discursos disponíveis no contexto sócio-histórico observado. As questões relacionadas ao conceito de identidade têm interessado a diferentes Ciências Humanas e Sociais, que, na contemporaneidade, tratam a identidade como instável, provisória, líquida, cultural e relacional (HALL, 2003; BAUMAN, 2005; CUCHE, 2002). Na LA, enfocamos a construção discursiva da identidade e, de acordo com Kleiman (1998b), entendemos que esta é "um conjunto de elementos dinâmicos e múltiplos da realidade subjetiva e social, uma condição transitória, moldada pelas relações sociais que, na percepção dos participantes, estão sendo construídas na interação" (VOVIO, DE GRANDE, 2010, p. 55).

No caso das identidades profissionais, como as de professor, médico, advogado; identidades reguladoras e avaliativas, como as que classificam e dividem uma turma em alunos bons ou ruins, são construídas, segundo Kleiman (2010, p.389),

diuturnamente em instituições formadoras, como a escola, as faculdades, enfim, nos espaços onde se ensina aos alunos a falar e pensar como os membros do grupo social, ou profissional, a que aspiram pertencer. Nesse processo, a interação é determinante, pois permite que os participantes se posicionem e sejam posicionados pelo outro, segundo relações de poder, status, hierarquia, gênero, etnia. 
Assim como Reichmann (2012), neste artigo, a noção da construção social de identidade profissional do professor é analisada na distribuição de vozes de outros (interiorizadas) e de si (internas) que ecoam em textos orais produzidos em entrevistas de autoconfrontação. Essas vozes, que sempre estão relacionadas a um contexto de produção, que fornecem parâmetros textuais, conforme Bronckart [1999; 2006]), "ora dissonantes e instáveis", provisoriamente elas se afinam, "(des) estabilizando construções identitárias" (REICHMANN, 2012, p. 936).

De acordo com Bakhtin (1988, p. 106), "todas as palavras e formas que povoam a linguagem são vozes sociais e históricas, que lhe dão determinadas significações concretas". Voz pode ser entendida, nesse sentido, como a vontade discursiva, a intenção, o tom dado ao enunciado. De acordo com Bronckart, as vozes "podem ser definidas como as entidades que assumem (ou às quais são atribuídas) a responsabilidade do que é enunciado" (BRONCKART, 1999, p. 326). O autor define algumas categorias para a constituição das vozes: a voz neutra (de narrador ou expositor); seguida de outras vozes infraordenadas em relação ao narrador/ expositor: vozes de personagens, vozes sociais e voz de autor empírico do texto.

Para analisar essas identidades construídas, precisamos considerar que a professora se depara com - e tem de se apropriar de - um instrumental teórico e metodológico que são novos para ela. A proposta de ensino de gêneros textuais da Engenharia Didática de Genebra é bastante conhecida e utilizada no contexto brasileiro, sendo revista e repensada por pesquisadores e professores do Brasil. Sua base teórico-metodológica tem origem em outra realidade de ensino, em outra história da escolarização - a escola suíça - e, visando ao desenvolvimento do professor brasileiro, precisam ser recontextualizadas na formação inicial e contínua de professores da educação básica.

Nas análises a seguir, enfocamos como Mirna constrói vozes de personagem e vozes de autor em oposições entre um "eu, professora" e o coletivo de trabalho, entre um antes e um depois do curso e em contraposição a vozes sociais mais amplas sobre o professor.

No excerto a seguir, trechos transcritos de uma entrevista de autoconfrontação, Mirna constrói uma contraposição entre um agir profissional anterior e um agir profissional posterior ao curso:

Excerto 1: Mudanças e o coletivo do trabalho

(12') Formadora/mediadora: O que ocasionou essas mudanças entre o que havia planejado e o que realmente realizou? 
Mirna: É claro que tinha que ter mudado a gente trabalha anos e anos fazendo de um jeito .... livro didático tá sempre pertinho... E o que nós temos como ferramenta didática? A lousa, o giz branco, uma sala de aula pequena que não dá pra fazer estudo em grupo... a gente até que pode ir pra sala de computador mas tem que buscar a chave e nem sempre a coordenadora está lá pra entregar, isso demora. Então eu peço pra eles fazerem em casa. eles tem computador e internet. fazem a tarefa na casa deles. a gente quer inovar aprendi isso aqui no curso... mas é complicado. A realidade é muito diferente. mas pode ser também que a gente tenha é medo... e então a gente se acomode nas coisas tradicionais.... (risos)

O enunciado de Mirna é marcado pela sua implicação no coletivo profissional (pelo uso recorrente de "nós", "a gente"), o que evidencia que, para ela, esse não é um problema que afeta somente o seu agir individual, mas também o agir coletivo de um grupo, do qual faz parte. Ela inicia sua resposta à formadora/mediadora da autoconfrontação ressaltando que "tinha que ter mudado". Modaliza o seu enunciado recorrendo à modalidade deôntica, que visa a regular o comportamento do interlocutor, o que parece responder a vozes sociais que cobram do professor uma renovação das práticas e da própria escola. Mirna responde a essa voz de cobrança e apelo à inovação, caracterizando as limitações das ferramentas didáticas de que dispõe na escola básica. Para isso, em praticamente todo o excerto, a voz de personagem é coletiva: não um eu-professora no presente (voz de autor), mas um nós (ou a gente), que remete aos problemas e "faltas" com as quais convivem os professores nos contextos de escola pública. Ela se insere no coletivo do trabalho e fala a partir desse lugar, como para compartilhar as responsabilidades e os impedimentos enfrentados. Cria-se uma oposição entre nós - professores - e vocês ou eles - experts, formadores, documentos oficiais, perspectivas teóricas, ou seja, aqueles que clamam por inovação das práticas escolares. A identidade profissional nesse excerto é construída na oposição entre esse "nós", professores da escola básica, e "eles", que cobram mudanças, voz desse outro que é interiorizada por Mirna.

A professora também recorre ao coletivo para justificar os motivos pelos quais retorna às práticas tradicionais ("coisas tradicionais"), desviando-se do trabalho planejado. A voz de autor, como professora, emerge apenas quando se refere a um pedido concreto que costuma fazer a seus alunos ("Então eu peço pra eles fazerem em casa").

No excerto a seguir, a identidade é construída em uma oposição entre o presente e o passado, entre um antes e depois do curso de formação continuada: 


\section{Excerto 2: Conflito entre o eu da sala de aula presente e passado}

(23') Professora-mediadora: Olha o comportamento dos alunos nesse momento... o que você diz deles nesse momento?

Prof. Mirna: Eles estão com cara aborrecida... entediada... essa turma não é de alunos barulhentos... até que são comportados. Mas to vendo que eu to meio perdida... quantas vezes eu já consultei o meu roteiro com a SD! A verdade é que a gente estranha muito... Encarar uma metodologia nova... ensinar sobre coisas diferentes! É difícil. Eu nunca trabalhei com um gênero textual dessa maneira.

(27’) Professora-mediadora: Como você fazia antes?

Prof. Mirna: antes ... eu pegava um gênero de texto do livro didático. Podia ser um conto uma fábula um poema ... e tirava do texto aquilo que eu ia trabalhar naquela aula... eu mostrava as coisas no texto pra eles. Um dia era a pontuação, outro dia os verbos, outro dia as orações coordenadas... mas esse jeito aí é difícil! E isso que as cartas do leitor estão ali na parede. Imagina trabalhar com texto na internet. Aqueles ODA que você falou tanto na sua disciplina... Nossa!

Ao responder à primeira pergunta e falar sobre seu agir, observado na gravação, Mirna assume uma voz de autor, de um "eu" no presente, pronome de autorreferência que indica que ela se constrói discursivamente como responsável pelo que diz, no controle de sua enunciação. Contudo, no momento em que passa a falar sobre as dificuldades trazidas pela apropriação de uma nova metodologia, volta a enunciar como um coletivo ("A verdade é que a gente estranha muito"), construindo uma voz de personagem coletiva, e salientando a ideia de que a dificuldade não é só dela, e sim do coletivo de trabalho dos professores da escola básica. A identidade de professor que volta ou permanece em práticas ditas "tradicionais" é, assim, dividida e compartilhada por Mirna com seus colegas.

A partir da segunda pergunta da professora/mediadora, concretiza-se mais fortemente a oposição entre um antes e um depois do curso de formação. Mirna descreve como costumava trabalhar e, para isso, só se utiliza da primeira pessoa do singular e verbos majoritariamente no pretérito imperfeito do indicativo. Ela estabelece uma oposição entre um passado recente e o futuro, representado por sua própria prática videogravada, a que ela se refere como "aí" - "mas esse jeito aí é difícil". Na continuação de sua fala, ela estabelece uma outra oposição entre o presente e um possível futuro, vislumbrado pelas discussões do curso ("Imagina trabalhar com texto na internet"). A voz do outro, da formadora e do próprio curso, 
é interiorizada e representada nesse momento como um possível vir a ser, mesmo que ainda representado como difícil, como ainda não conquistado.

Tais contraposições de vozes indiciam tensões que ora sinalizam conflitos, ora constituem ressignificações do que é ser docente ou do que pode vir a ser um outro docente. É na autoconfrontação que Mirna toma consciência em resposta à voz do outro - da própria formadora, dos alunos, do coletivo de trabalho e de vozes sociais que julgam, avaliam e cobram o professor. Dessa maneira, apesar de muitas vezes não construir identidade fortalecida na contraposição com esse outro (teorias, universidade, experts, documentos oficiais), ela constrói agentividades, mesmo que provisórias, pois consegue analisar a si mesma, mas também analisa o coletivo do trabalho, as condições da instituição escolar e o discurso acadêmico.

A identidade profissional fortalecida durante anos de experiência profissional é agora questionada na relação com o mundo discursivo da academia: Como enfrentar os desafios dos novos materiais do paradigma da aprendizagem interativa? Como ultrapassar a submissão às culturas do impresso e de massas (de transmissão de um para muitos) para fazer adentrar os novos letramentos na escola?

Ao construir a oposição entre um antes e um depois, Mirna toma consciência das diferenças, como também das próprias possibilidades de seu agir dentro do contexto em que se realiza. As tensões vivenciadas pela prof. Mirna ao receber a proposta de trabalho com gêneros textuais organizada em sequências didáticas, de um lado, e do paradigma de aprendizagem interativo, de outro, são pontos que consideramos importantes para essa reflexão porque ela precisou: a) demonstrar autonomia em relação ao livro didático que a acompanha há décadas; b) planejar atividades didáticas mediadas pelas ferramentas digitais que adentraram na vida dos alunos nos últimos anos (TV, internet, celulares e computadores); c) ultrapassar a abordagem das tipologias textuais; d) compreender que nem sempre é necessário iniciar a sequência didática pela avaliação inicial das capacidades dos alunos; e) implementar a diversificação das formas sociais de trabalho entre os alunos na aula; f) pensar o ensino da escrita na sua dimensão "comunicacional", , o que implica a exploração da escrita orientada para um destinatário concreto, real ou virtual.

A complexidade desse processo traz consigo a vivência de um conflito identitário profissional entre a identidade de professora segura e com autoestima elevada, anterior ao curso, e a identidade de professora em formação, em uma

6. No processo de aprendizagem, Schneuwly (1985) postula que a escola deveria pensar o ensino da escrita na sua dimensão "comunicacional", que implica a exploração da escrita orientada para o outro, para um interlocutor concreto, real ou virtual, a quem nos dirigimos e que constitui também o nosso dizer. 
relação de subalternidade ao saber acadêmico, visto como mais prestigiado. Ela mergulha em um lugar em que há um trabalho prescrito pelos documentos oficiais e pelos experts externos - a formadora-orientadora e os referenciais teóricos -, e precisa reconstruir uma identidade profissional ao se apropriar desses saberes, articulados aos saberes experienciais e disciplinares que já construiu ao longo de vinte anos de carreira, processo que não é simples e que precisa ser considerado nas formações oferecidas a professores.

A professora Mirna, antes de seu ingresso no curso de formação contínua, definia-se como professora pelo mundo discursivo de uma escola em uma pequena cidade do interior do Paraná. Com o ingresso, passa a frequentar uma cidade maior, um centro da região, e uma grande e prestigiada universidade pública. Os espaços em que passa a interagir são constituídos de outros mundos discursivos, principalmente o acadêmico.

Dessa maneira, a autoconfrontação, o falar sobre si mesma como profissional, possibilita a abertura a revisões e questionamentos constantes. Nesse processo, não só a aula em si, como texto oral, é revisada, mas a própria identidade profissional é reconstruída, negociada, podendo forjar novas experiências. Mirna enuncia os limites das transformações, que não dependem apenas do conhecimento construído a respeito das metodologias de ensino, do processo de aprendizagem e de paradigmas alternativos, mas também dos limites da esfera escolar, que possui especificidades a serem consideradas.

De alguma maneira, o conflito entre o que era, o que é e o que pode vir a ser possibilita o densenvolvimento da professora, já que este se dá, como nos ensina Bronckart (2008), nesse movimento de atribuição de significações ao agir.

\section{CONSIDERAÇÕES FINAIS}

Com o objetivo de discutir as identidades docentes construídas, negociadas e disputadas no processo de inserção de uma professora da escola básica em um curso de Mestrado Profissional, analisamos as representações do agir construídas por uma professora ao participar de maneira periférica ou centralmente de mundos sociais e discursivos diferentes, a escola e a universidade.

$\mathrm{Na}$ interação com a formadora durante entrevistas de autoconfrontação ao trabalho realizado na sala de aula, a professora pode falar sobre si, sobre seu agir, atribuir a ele significações e mobilizando diferentes vozes e se posicionando em relação às avaliações que elas expressam. Ela se reconstrói identitariamente como professora e faz das contradições conflituosas que vivencia uma ferramenta potencial para o seu desenvolvimento profissional, uma vez que delas tome consciência. 
As práticas de formação docente, ao assumirem posturas prescritivas, descendentes e impositivas que buscam descrever e impor a verdade (o que ensinar, como ensinar, como transformar práticas do paradigma de aprendizagem curricular, como pilotar projetos pedagógicos, como didatizar práticas sociais de usos da linguagem, etc.) não podem negligenciar os conflitos identitários dos sujeitos nelas envolvidos, cujas identidades são construídas em outro mundo discursivo - a escola, principalmente, preocupação esta que dá um lugar de relevância à mediação do formador nos processos formativos.

\section{REFERÊNCIAS BIBLIOGRÁFICAS}

BAKHTIN, M. (1934). O discurso no romance. In: Questões de Literatura e Estética. São Paulo: Hucitec, 1988.

BAUMAN, Z. (2005). Identidade: entrevista a Benedetto Vecchi. Tradução de Carlos Alberto Medeiros. Rio de Janeiro: Jorge Zahar Ed.

BRONCKART, J. P. (2012) Um retorno necessário à questão do desenvolvimento. In: BUENO, L. ; TEIXEIRA, M.A.; CRISTOVÃO, V. L. L.(orgs.) .Gêneros textuais e formação inicial: uma homenagem a Malu Matêncio Campinas: Mercado de Letras, p. 85-109.

BRONCKART, J. P. (2008). O agir nos discursos: das concepções teóricas às concepções dos trabalhadores. Tradução de Anna Rachel Machado e Maria de Lourdes Meirelles Matêncio. Campinas, SP: Mercado das Letras.

BRONCKART, J. P. (2006). Atividade de linguagem, discurso e desenvolvimento humano. Tradução de Anna Rachel Machado, Maria de Lourdes Meirelles Matencio. Campinas: Mercado das Letras.

BRONCKART, J. P. (2003). Atividade de linguagem, textos e discursos: por um interacionismo sociodiscursivo. Tradução de Anna Rachel Machado, Péricles Cunha. São Paulo: EDUC.

BRONCKART, J. P. (1999). Atividades de linguagem, textos e discursos: por um interacionismo sócio-discursivo. Tradução de Anna Rachel Machado; Péricles Cunha. São Paulo: EDUC, 2003.

BRONCKART, E. B.; BRONCKART, J-P. (2017). As representações do agir educacional no quadro do gênero entrevista. In GUIMARÃES, A. M. de M.; LOUSADA, E. 
G.; BUENO, L. As unidades semióticas em ação: estudos linguísticos e didáticos na perspectiva do interacionismo sociodiscursivo. Campinas, SP: Mercado de Letras.

CLOT, Yves. (2006). A função psicológica do trabalbo. Tradução de Adail Sobral. Petrópolis: Vozes, 2006.

CLOT, Yves. (2010). Gêneros profissionais e estilos da ação. In: Trabalho e poder de agir. Tradução de Guilherme João de Freitas Teixeira e Marlene Machado Zica Vianna. Belo Horizonte: Fabrefactum, 2010, p. 117-154.

CUCHE, D. (2002). A noção de cultura nas ciências sociais. 2 ed. Bauru, SP: EDUSC, 2002.

DOLZ, J. (2016). As atividades e os exercícios de língua: uma reflexão sobre a engenharia didática. DELTA, vol.32, no.1. São Paulo, jan./abr. 2016.

DOLZ, J.; GAGNON, R. (2015). O gênero de texto, uma ferramenta didática para desenvolver a linguagem oral e escrita. Tradução de Anna Rachel Machado e Carla Messias). In: L. Bueno \& T. C. Costa Hubes (orgs.). Gêneros orais no ensino. Campinas, SP: Mercado de Letras. p. 23-56.

HALL, S. (1998). Tradução de Tomaz Tadeu da Silva e Guacira Lopes Louro. . Tradução de Tomaz Tadeu da Silva e Guacira Lopes Louro. $2^{\text {a }}$ ed. Rio de Janeiro: DP\&A.

HILA, Claudia Valéria Doná. (2009). O microensino como instrumento de formação do professor de língua portuguesa. Acta Scientiarum. Human and Social Sciences. Maringá, v. 31, n. 1, p. 33-41.

HOLLAND, D. et. al. (2003). Identity and agency in cultural worlds. Havard University Press. 4 ed.

KLEIMAN, A., VIANNA, C., DE GRANDE, P. B. (2013). "Sem querer ir contra pessoas tão ilustres...": construção e negociação identitárias do professor entre discursos de (des)legitimação. Scripta. V.17, n. 32.

KLEIMAN, A. (1998a). O estatuto disciplinar da Linguística Aplicada: o traçado de um percurso. Um rumo para o debate. In: SIGNORINI, I. e CAVALCANTI, M. (orgs.) Linguística aplicada e transdisciplinaridade: questões e perspectivas. Campinas: Mercado de Letras.

KLEIMAN, A. (1998b). A construção de identidade em sala de aula: um enfoque interacional. In: SIGNORINI, I, (org.) Língua(gem) e identidade. Campinas, SP: Mercado de Letras. 
KLEIMAN, A. (2009). Trajetórias de acesso ao mundo da escrita: relevância das práticas não Projetos dentro de projetos: ensino-Aprendizagem da escrita na formação de professores de nível universitário e de outros agentes de letramento. Scripta, Belo Horizonte, v. 13, n. 24, p. 17-30, $1^{\circ}$ sem.

KLEIMAN, A. (2010). Trajetórias de acesso ao mundo da escrita: relevância das práticas não escolares de letramento para o letramento escolar. PERSPECTIVA, Florianópolis, v. 28 , n. $2,375-400$, jul./dez.

KLEIMAN, A. (2013). Agenda de pesquisa e ação em Linguística Aplicada: problematizações. In: MOITA LOPES, L. P. Linguística aplicada na modernidade recente: festschrift para Antonieta Celani. São Paulo: Parábola.

LEMKE, J. (2010). Letramento metamidiático: Transformando significados e mídias. Trabalhos em Linguística Aplicada, vol. 49/2. Campinas, SP: DLA/IEL/UNICAMP, p. 1-17.

MACHADO, A. R. (2007). Por uma concepção ampliada do trabalho do professor. In: GUIMARÃES, Ana Maria de Matos; MACHADO, Anna Rachel, COUTINHO, Antônia (Orgs). O interacionismo Sociodiscursivo: questões epistemológicas e metodológicas. Campinas, São Paulo: Mercado das Letras.

NASCIMENTO, E.L. (2014). A formação contínua como objeto de investigação: o agir (re) configurado nos gestos profissionais. In: NASCIMENTO, E. L.; ROJO R. (Org.). Gêneros de texto/discurso e os desafios da contemporaneidade. Campinas: Pontes Editores.

REICHMANN, Carla Lynn. (2012). Práticas de letramento docente no estágio supervisionado de letras estrangeiras. Revista Brasileira de Linguística Aplicada, Belo Horizonte, v. 12, n. 4, p. 933-954.

ROJO, R. (2017). Entre plataformas, ODAS, e protótipos: novos multiletramentos em tempos de WEB2. The ESPecialist: Descrição, Ensino e aprendizagem. Vol. 38, n. 1, jan-jul 2017, pp.1-20.

ROJO, R. (2012). Pedagogia dos Multiletramentos: Diversidade cultural e de linguagens na escola. In: ROJO, R. H. R.; MOURA, E. (Orgs.) Multiletramentos na Escola. SP: Parábola, 2012, pp. 11-32.

ROJO, R. (2013). Materiais didáticos no ensino de línguas. In: MOITA-LOPES, L. P. (Org.) Linguística Aplicada na Modernidade Recente - Festschrift para Antonieta Celani. São Paulo, SP: Parábola Editorial/Cultura Inglesa, pp. 163-196. 
SCHNEUWLY, B.; DOLZ, J. (2004). Gêneros orais e escritos na escola. Tradução de Roxane Rojo, Glaís Sales Cordeiro. São Paulo: Mercado da Letras.

SCHNEUWLY, B. (2009). Le travail enseignant. In: SCHNEUWLY, B.; DOLZ, J. Des objets enseiginés en classe de français. Rennes: Presses Universitaires de Rennes.

SCHNEUWLY, B. (2009). Des objets enseiginés en classe de français. Rennes: Presses Universitaires de Rennes.

SCHNEUWLY, B. (2009). Le travail enseignant. In: SCHNEUWLY, B.; DOLZ, J. Des objets enseiginés en classe de français. Rennes: Presses Universitaires de Rennes

SCHNEUWLY, B.; DOLZ, J.; NOVERRAZ, M. (2004). Sequências didáticas para o oral e a escrita: apresentação de um procedimento. In: SCHNEUWLY, B. e DOLZ, J. e colaboradores. Gêneros orais e escritos na escola. Tradução e organização de Roxane Rojo e Glaís S. Cordeiro. Campinas, SP: Mercado de Letras.

VÓVIO, C. L.; DE GRANDE, P. B. (2010). O que dizem as educadoras sobre si: construções identitárias e formação docente. In: VÓVIO, C. L.; SITO, L.; DE GRANDE, P. B. (Org.). Letramentos: rupturas, deslocamentos e repercussões de pesquisas em LA. Campinas: Mercado de Letras. p. 51-70.

WOODWARD, H. (2000). Identidade e diferença: uma introdução teórica e conceitual. In: SILVA, TOMAZ TADEU (Org). Identidade e diferença: a perspectiva dos Estudos Culturais. Petropolis, RJ: Vozes.

Recebido: 19/02/2018

Aceito: 05/03/2018 